\title{
Does Crime Pay? \\ A Classroom Demonstration of Monitoring and Enforcement
}

\author{
Lisa R. Anderson \\ College of William and Mary \\ Sarah L. Stafford \\ College of William and Mary
}

College of William and Mary

Department of Economics

Working Paper Number 17

May 2005

The authors thank members of Stafford's Fall 2004 and Spring 2005 Law and Economics classes and of Anderson's Spring 2005 Experimental Economics class for their feedback. Support from the National Science Foundation (SES 334851) is gratefully acknowledged. 
COLLEGE OF WILLIAM AND MARY

DEPARTMENT OF ECONOMICS

WORKING PAPER \# 17

May 2005

\title{
Does Crime Pay? \\ A Classroom Demonstration of Monitoring and Enforcement
}

\begin{abstract}
This paper presents a classroom game in which students choose whether or not to comply with pollution regulations. By changing the level of monitoring and fines for noncompliance across periods, the game shows students how the probability and severity of enforcement affects incentives for compliance. The game can be adapted for settings other than environmental regulation and can be used in a variety of classes including regulation, law and economics, environmental economics, public economics, or the economics of crime. It can easily be conducted in a fifty-minute class period.
\end{abstract}

JEL Codes: A22, C90, K42

Keywords: Classroom Experiment, Non-Compliance, Pollution

Lisa R.Anderson

Department of Economics

College of William and Mary

P.O. Box 8795

Williamsburg, VA 23187-8795

1rande@wm.edu
Sarah L. Stafford (corresponding author)

Department of Economics

College of William and Mary

P.O. Box 8795

Williamsburg, VA 23187-8795

slstaf@wm.edu 


\section{Introduction}

Enforcement of laws and regulations is a relevant topic in many economic courses including regulation, law and economics, environmental economics and the economics of crime. Although Gary Becker's (1968) seminal model on the economics of crime and punishment should be accessible to most classes, there are a number of interesting and important aspects of enforcement that cannot be easily demonstrated through basic models. This paper presents a classroom game that highlights some of those aspects including the dynamics of enforcement, enforcement strategies that take past compliance behavior into account, and the effect of changing the probability of monitoring as well as the severity of enforcement. Moreover, the game highlights areas where actual behavior may differ from the predictions of theoretical models as students often react differently to changes in monitoring probability relative to changes in enforcement severity.

\section{Conducting the Demonstration}

This game is designed for 20 "companies" which may consist of one or more students, although we recommend no more than three students per company to ensure that each student is involved in the decision making process. ${ }^{1}$ Additionally, you will need at least one student to help run the game. The game can be conducted with printed instructions, record sheets, paper, envelopes, and some means of random selection such as bingo balls or scrabble tiles.

In this game companies are subject to environmental regulations which require pollution to be remediated. Each period companies must decide whether or not to comply with the regulations. Because pollution removal costs $\$ 100$, in the absence of enforcement non-

\footnotetext{
${ }^{1}$ The game can be run with fewer companies for smaller classes or if you want students to work in groups.
} 
compliance is more profitable than compliance. However, the regulatory agency does have an enforcement program. Thus companies have to weigh the cost of compliance against the expected cost of noncompliance. Each period, the agency's enforcement strategy is announced prior to the companies choosing whether to comply. After companies have made their decisions, the announced strategy is implemented. This design allows students to think about the behavioral implications of various enforcement strategies. Additionally, behavior that is inconsistent with theoretical predictions is likely to occur, which allows for a rich discussion of enforcement in general and how enforcement strategies can be modified to be more effective.

Before class, determine how many companies you will have and approximately how many students will comprise each company. ${ }^{2}$ If you are going to use a numerical random selection device such as bingo balls, number the companies. Alternatively, give each company a name starting with a different letter of the alphabet and use scrabble ties as your selection mechanism. To begin the game, distribute the instructions to each student and a record sheet to each company. ${ }^{3}$ Additionally, give each company an envelope labeled with their name or number that contains two cards of different colors also marked with the company initial or number. We have used index cards with "Continue to Pollute" written in red and "Pollution Removal" written in green.

Read the instructions out loud to the class and answer any initial questions. ${ }^{4}$ Make sure that students understand that the regulator can only obtain information through monitoring and

\footnotetext{
${ }^{2}$ However, if fewer students attend class than anticipated, the game can easily be conducted with fewer companies without the need for modifications (as explained in footnotes throughout the text).

${ }^{3}$ In our experience financial rewards are not necessary to motivate students in classroom games, but to increase interest, you can offer to pay a randomly selected company a small percentage of earnings.

${ }^{4}$ If you have fewer companies than planned, announce before beginning the game that X companies are located in a different county and thus while they are not in the room, they are subject to the enforcement process. Therefore if the probability of inspection is 1 in 20 , all 20 companies - not just those present in the classroom - are equally likely to be inspected.
} 
that only current behavior can be observed. Once all questions are answered, begin the game by reiterating the baseline enforcement strategy described in the instructions, that is that one of the 20 companies will be randomly selected for inspection and if found to be in noncompliance will be fined $\$ 1000$. As the regulator you should then turn your back or leave the room while each company indicates its decision by holding up one of the two cards. ${ }^{5}$ The student assistant should record each decision on the record sheet provided in the appendix. Once decisions are recorded, randomly select one company to inspect. ${ }^{6}$ Ask the student assistant to announce that company's compliance status, and if the company is noncompliant remind them that they have been fined $\$ 1000$ and must write the fine amount down on their record sheet. Also have the assistant report overall compliance - number of companies in compliance and number that are not compliant and write that information on the board or on an overhead.

At the beginning of each period, announce the regulatory strategy and have companies make their compliance decisions. Table 1 presents a suggested plan of enforcement strategies, although it is easy to develop alternative strategies if you want to focus the discussion on a particular type of enforcement. After the first period or two, it should take less than 2 minutes to complete each period. In testing this demonstration, we found it to be particularly effective if we implied that changes in the enforcement regime were influenced by past compliance behavior rather than following some predetermined schedule. For example, after round two you may want to say that you are increasing the fine level to see whether that will increase the level of compliance.

\footnotetext{
${ }^{5}$ Make sure that the company initial or number on the cards is large enough so that it can be read by the assistant from the front of the class. Alternatively, the assistant may call each company's name or number in order and then have the company reveal their choice by holding up the appropriate color card.

${ }^{6}$ If you have fewer than 20 companies in your class, you may not end up inspecting anyone in the class, since you might randomly select one of the fictitious companies in the other county to inspect.
} 
Table 1: Suggested Enforcement Strategies

\begin{tabular}{|c|c|c|c|}
\hline Day & $\begin{array}{l}\text { Probability } \\
\text { of Inspection }\end{array}$ & Severity of Fine & Comments \\
\hline 1 & 1 in $20(0.05)$ & $\$ 1000$ & Noncompliance is profit-maximizing. \\
\hline 2 & 1 in $20(0.05)$ & $\$ 1000$ & $\begin{array}{l}\text { Same as day } 1 . \text { Allows you to see if } \\
\text { any companies change decision. }\end{array}$ \\
\hline 3 & 1 in $20(0.05)$ & $\$ 2000$ & $\begin{array}{l}\text { Noncompliance provides same } \\
\text { expected benefit as compliance. }\end{array}$ \\
\hline 4 & 1 in $20(0.05)$ & $\$ 2000$ & $\begin{array}{l}\text { Same as day } 3 \text {. Allows you to see if } \\
\text { any companies change decision, } \\
\text { particularly the one that was inspected } \\
\text { in period } 3 \text {. }\end{array}$ \\
\hline 5 & 2 in $20(0.10)$ & $\$ 2000$ & Compliance is profit-maximizing. \\
\hline 6 & 2 in $20(0.10)$ & $\$ 2000$ & Same as day 5. \\
\hline 7 & 2 in $20(0.10)$ & $\$ 1000$ & $\begin{array}{l}\text { Noncompliance provides same } \\
\text { expected benefit as compliance. } \\
\text { Can compare to periods } 3 \text { and } 4 \text { to see } \\
\text { if there is a difference in the effect of } \\
\text { punishment probability and } \\
\text { punishment severity. }\end{array}$ \\
\hline 8 & 2 in $20(0.10)$ & $\$ 1000$ & Same as day 7 \\
\hline 9 & 1 in 20 & $\begin{array}{l}\$ 1000 \text { for } 1^{\text {st }} \text { time offenders; } \\
\$ 2000 \text { for } 2^{\text {nd }} \text { time offenders; } \\
\$ 5000 \text { for } 3^{\text {rd }} \text { time (or greater) } \\
\text { offenders }\end{array}$ & $\begin{array}{l}\text { Fines depend on compliance history } \\
\text { (as revealed by an inspection). } \\
\text { Noncompliance optimal only for } \\
\text { companies with clean records. For } \\
\text { those with past violations, compliance } \\
\text { is at least as profitable as } \\
\text { noncompliance. }\end{array}$ \\
\hline 10 & 1 in 20 & $\begin{array}{l}\$ 1000 \text { for } 1^{\text {st }} \text { time offenders; } \\
\$ 2000 \text { for } 2^{\text {nd }} \text { time offenders; } \\
\$ 5000 \text { for } 3^{\text {rd }} \text { time (or greater) } \\
\text { offenders }\end{array}$ & Same as day 9. \\
\hline
\end{tabular}

Figure 1 presents the results from the Spring 2005 Law and Economics class at William and Mary using the enforcement strategies suggested in Table 1. We have conducted versions of this experiment in several other classes with similar results. 
Figure 1

Sample Results using Suggested Enforcement Strategies

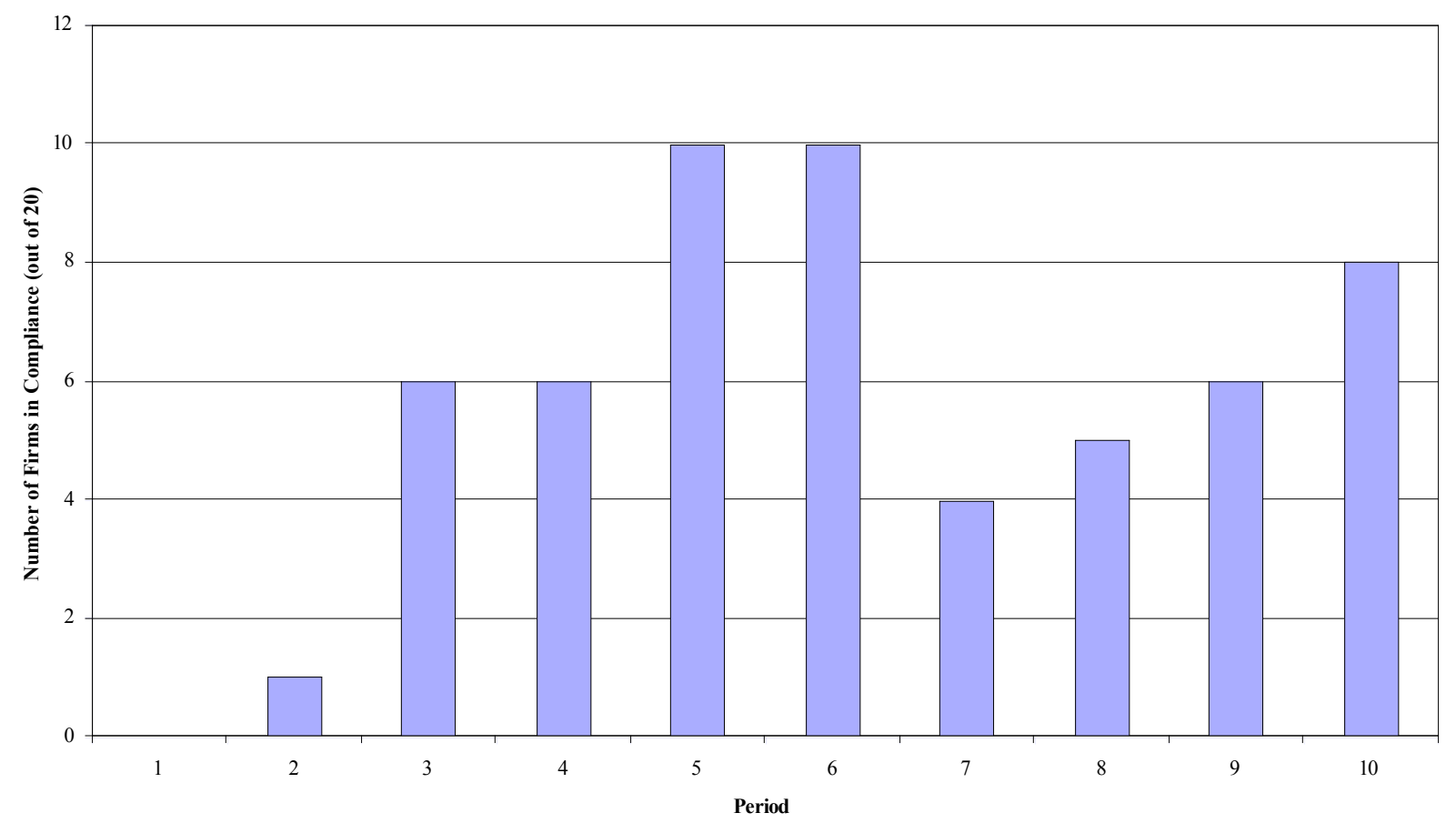

\section{Class Discussion}

As a first step, have students determine what expected punishment makes it optimal for companies to comply in a one-shot game. Compare this with the results from the demonstration. Is there over compliance or under compliance in general? Ask students what factors would contribute to over compliance and what would contribute to under compliance.

Next, focus on the students' responses to increases in the probability of monitoring relative to increases in the severity of the fine. Does one appear to be more effective than another? In research experiments using a public goods context, Anderson and Stafford (2003) find that subjects respond more to punishment severity than probability. Block and Gerety (1995) examine this same question using a collusion framework and find that undergraduate students are more deterred by the severity of the punishment than the probability but that the opposite is true 
for inmates at a correctional facility. Discuss how such results relate to risk aversion and riskloving behavior and ask students to characterize their risk attitudes in this demonstration based on the results. You might also discuss how risk preferences would differ for actual companies as opposed to individuals.

Another interesting topic of discussion is how the announcement of compliance status for the monitored companies affected students' decisions. Were they embarrassed to be caught polluting? Alternatively, did some feel proud to have been caught polluting? Would real companies have a similar reaction? Ask students to think about the difference between the stigma associated with being caught compared to other monetary effects that could result from negative publicity, such as decreases in consumer demand or a drop in stock prices for noncompliant companies.

The dynamic nature of the demonstration provides another area for discussion. Ask students who had been inspected how that changed their future behavior. Did anyone think "lightening doesn't strike twice" after being inspected or caught? How about feeling that they were on a "losing streak"? We have found that having been caught generally does not result in more compliance unless past violations increase future punishment. As one student remarked after having been caught polluting twice in a row, "I felt I had to make up for last time." However, when the enforcement strategy includes escalating fines for past violations, we generally find that students alter their compliance behavior. Check to see if all students changed their behavior or if only students who had been caught in the past became more compliant on average.

\footnotetext{
${ }^{7}$ Anderson and Stafford (2003) find that past punishment decreases compliance (defined in the context of their experiment as contributions to a public good) while a number of tax experiments have found that compliance improves among participants that had been audited (see Andreoni, Erard, and Feinstein (1998), page 843).
} 


\section{Extensions and Variations}

\section{Asymmetric Costs}

While the game is currently set up in the context of environmental regulation, the story can easily be told in the context of a restaurants and health inspections, factories and safety inspections, tax payers and audits, etc. Regardless of the context, in more advanced classes you may want to vary the costs across companies. For example, you could make some companies organic chemical manufacturers and some paper producers and have different costs for the two types of companies. Not only does this demonstrate the idea the one should not expect all companies to be equally compliant, it can also lead into a discussion of targeting based on characteristics that are likely to be correlated with compliance cost.

\section{Targeted Enforcement}

Another method for opening the discussion to targeting is to introduce a targeted enforcement scheme as follows. After several periods - once three or four companies have been found to be noncompliant - announce that half of all companies that have been caught in the past (or one out of three, depending on the number of companies that have been caught) will now be inspected each period and for those that have never been caught, only one will be selected at random to be inspected. This scenario mimics that of Harrington's targeted enforcement model with "good" and "bad" groups. ${ }^{8}$ Given this setup, compliance among the bad companies will be profit maximizing while noncompliance is likely to be more profitable for the good group. We have found that companies quickly reverse their past compliance strategies with good companies becoming more likely to pollute and bad companies choosing to comply.

\footnotetext{
${ }^{8}$ See Harrington (1988) for a description of this model.
} 


\section{Contestable Fines}

For a law and economics class you may want to revise the game in two ways. First, allow companies to contest their fines for a fee of $\$ 750$. If a company contests, roll a six sided die. If the die shows one or two, the company does not have to pay the fine (but it does have to pay \$750). ${ }^{9}$ If the die shows three or four, the fine is cut in half. If the die shows five or six, the company must pay the entire fine. In addition to compliance, track how often companies contest the fine. After all results have been collected, reveal costs that the regulators must pay for inspections and for defending fine assessment. For example, you could assume that each inspection costs $\$ 200$ and that defending against a company contesting its fine costs $\$ 500$. Use these costs along with the results to calculate the cost effectiveness of various enforcement schemes, or assign the calculations as a homework exercise. ${ }^{10}$

\section{A Public Goods Variation}

As described above, this exercise assumes away complicated interactions between companies. However, in a public economics class you might prefer to implement our monitoring and punishment scheme in the context of a public goods game. Explain that each company is located along the same river and has an option to abate pollution within their factory (at a high cost to that particular company) or pollute the nearby river. Toxins in the river cannot be tracked to a particular company, so all companies must share equally in the cost of cleaning up pollution in the river. You can keep the per-period profit at $\$ 1000$ and the in-company abatement cost at $\$ 100$. However, if a company chooses not to abate pollution within its factory, it causes $\$ 200$ worth of damage to the nearby river. Since river pollution cannot be tracked to a particular

\footnotetext{
${ }^{9}$ In this setup, contesting is profitable when fines are greater than $\$ 1,500$.
} 
company, all companies must share equally in the clean up expense (at $\$ 200 / 20=\$ 10$ per company). ${ }^{11}$

Start the exercise by conducting two periods with this new structure and without monitoring or enforcement. After round two announce that pollution regulations will be enforced (as described in the instructions in the appendix with a $\$ 1000$ cost for non-compliance within the factory) then continue through the suggested enforcement plan in Table 1. Given the combinations of probability and severity of enforcement, it is individually optimal for companies to be non-compliant for the first four periods listed in table 1 and they are indifferent in suggested treatments five through eight. As in the basic treatment, optimal behavior depends on past actions when you implement an increasing fine structure.

This variation of the game allows you to discuss compliance with environmental regulations as a public good and to explore monitoring as a possible solution to the free rider problem. You can point out that the decision problem without regulation is a prisoner's dilemma in the sense that it is individually optimal for each company to pollute the river regardless of the choices of other companies (since the $\$ 100$ in-company abatement cost is lower than the $\$ 10$ per company cost for river clean-up). However, all companies make more profit when all pollution abatement is done within factories ( $\$ 900$ versus the $\$ 800$ profit if all companies pollute the river). With interdependence of profits across companies, it is also interesting to fix the monitoring probability and fine amount for several rounds and vary whether or not there is an

\footnotetext{
${ }^{10}$ This could also be assigned as homework for classes that participate in the standard form of the game. Have students calculate who should contest and, assuming no changes in behavior, how this would affect revenue collection and enforcement costs for each period.

${ }^{11}$ You should modify the record sheet in the appendix to reflect this change in the game. Change the column (B) heading to "In-Company Pollution Removal" and add two new columns between columns (B) and (C). The new column (C) should be labeled "Number of Companies Not Performing In-Company Pollution Removal," and the new column (D) should be labeled "Cost of Cleaning the River $=(C) * \$ 200 / 20 "$ ". If you have fewer than 20 companies in your class, you may want to adjust the cost of abatement for pollution in the river.
} 
announcement about the compliance status of the monitored company(s). This will allow you to determine if punishment and announcement have different effects on compliance behavior. You might find that students are more compliant when there is a chance that they will be exposed as free riders.

\section{Concluding Remarks}

This paper describes an exercise that demonstrates several important aspects of regulatory design. By choosing whether to comply with a costly regulation or risk a larger fine, students react to a variety of enforcement schemes. This exercise motivates discussion about the relative effectiveness of increasing the probability of monitoring verses increasing fines for noncompliance. Further, the dynamic nature of the game allows students to think about how past experiences affect compliance behavior. The simplicity of the basic setup makes this exercise very easy to adapt for more specialized topics like targeted enforcement, a fine system that is based on past behavior, and compliance as a public good. 


\section{References}

Anderson, Lisa R. and Sarah L. Stafford. (2003). "Punishment in a Regulatory Setting: Experimental Evidence from the VCM," Journal of Regulatory Economics, 24:91-110.

Andreoni, James, Brian Erard and Jonathan Feinstein. (1998). "Tax Compliance," Journal of Economic Literature, 36:818-860.

Becker, Gary (1968), “Crime and Punishment: An Economic Approach,” Journal of Political Economy, 76:169-172.

Block, Michael K. and Vernon E. Gerety. (1995). "Some Experimental Evidence on Differences Between Student and Prisoner Reactions to Monetary Penalties and Risk," Journal of Legal Studies, 22:123-138.

Harrington, Winston. (1988) "Enforcement Leverage When Penalties Are Restricted," Journal of Public Economics, 37:29-53. 


\section{Instructions}

You own a small business that earns revenues of $\$ 1000$ a day net of all production costs. State environmental regulations require that you remove pollution from your wastewater before returning the wastewater to the river that adjoins your factory. Pollution removal costs $\$ 100$ a day above your production costs.

Pollution regulations are enforced by the county environmental protection agent. There are a total of 20 businesses in the county that are subject to the same regulation. The agent can inspect one factory a day, and chooses randomly each morning which factory to visit by drawing the name of one factory from an urn containing the names of all 20 businesses. If the agent inspects your factory and you have not conducted pollution removal, you will be fined $\$ 1000$. If the agent inspects your factory and you have conducted pollution removal, you will pay no fine.

Discuss with your board of directors whether or not you will conduct pollution removal today. Once all companies have made a decision, the regulator will face the board and you should indicate what you want to do by holding up either a green "Pollution Removal" card or a red "Continue to Pollute" card. The assistant (not the county regulator) will record your decision and track overall pollution levels. However, the assistant cannot report any of what he or she sees to the county regulator, so if your factory was not inspected you cannot be fined and the information on the assistant's record sheet cannot be used against your business. Once the assistant records your decision, put your card back in the envelope. If you conducted pollution removal, record the $\$ 100$ cost on the Record Sheet in column B for Day 1.

After all businesses have made their pollution removal decision and the decisions have been recorded by the assistant, the county regulator will draw a business name and inspect their factory. If the factory has not conducted pollution removal it will be assessed a fine. 
Record Sheet

Company Name:

\begin{tabular}{|c|c|c|c|c|c|}
\hline Day & $\begin{array}{c}\text { Net Daily } \\
\text { Revenue } \\
\text { (A) }\end{array}$ & $\begin{array}{c}\text { Pollution } \\
\text { Removal Cost } \\
\text { (B) }\end{array}$ & Fines Paid & Daily Profit & $\begin{array}{c}\text { Cumulative } \\
\text { Profit } \\
\text { (E) }\end{array}$ \\
\hline 1 & $\$ 1000$ & & & & (C) \\
\hline 2 & $\$ 1000$ & & & & \\
\hline 3 & $\$ 1000$ & & & & \\
\hline 4 & $\$ 1000$ & & & & \\
\hline 5 & $\$ 1000$ & & & & \\
\hline 6 & $\$ 1000$ & & & & \\
\hline 7 & $\$ 1000$ & & & & \\
\hline 8 & $\$ 1000$ & & & & \\
\hline 10 & $\$ 1000$ & & & & \\
\hline
\end{tabular}


Assistant's Record Sheet

\begin{tabular}{|c|c|c|c|c|c|c|c|c|c|c|}
\hline Company & Day 1 & Day 2 & Day 3 & Day 4 & Day 5 & Day 6 & Day 7 & Day 8 & Day 9 & Day 10 \\
\hline 1 & & & & & & & & & & \\
\hline 2 & & & & & & & & & & \\
\hline 3 & & & & & & & & & & \\
\hline 4 & & & & & & & & & & \\
\hline 5 & & & & & & & & & & \\
\hline 6 & & & & & & & & & & \\
\hline 7 & & & & & & & & & & \\
\hline 8 & & & & & & & & & & \\
\hline 9 & & & & & & & & & & \\
\hline 10 & & & & & & & & & & \\
\hline 11 & & & & & & & & & & \\
\hline 12 & & & & & & & & & & \\
\hline 13 & & & & & & & & & & \\
\hline 14 & & & & & & & & & & \\
\hline 15 & & & & & & & & & & \\
\hline 16 & & & & & & & & & & \\
\hline 17 & & & & & & & & & & \\
\hline 18 & & & & & & & & & & \\
\hline 19 & & & & & & & & & & \\
\hline 20 & & & & & & & & & & \\
\hline
\end{tabular}

